\title{
A Sustainability Index tool for measuring the Environmental performance of a metropolitan city
}

\author{
Akshay Dhawan ${ }^{1, *}$, Nakul Gupta ${ }^{1}$, Kuldeep K. Saxena ${ }^{2}$, and Rajesh Goyal ${ }^{3}$ \\ ${ }^{1}$ Department of Civil Engineering, GLA University Mathura, 281406, India \\ ${ }^{2}$ Department of Mechanical Engineering, GLA University Mathura, 281406, India \\ ${ }^{3}$ Construction and Project Management, NICMAR Delhi NCR, Bahadurgarh 124507, India
}

\begin{abstract}
This paper targets estimating and evaluating the Indian Cities on the natural execution rules across an expansive scope of classifications and supporting markers. Metropolitan urban areas have different Environmental issues like never-ending suburbia, Deprive of green and characteristic gaps, insufficient $\mathrm{H} 2 \mathrm{O}$ supply, sewage water, solid refuse, contamination of air and soil. To combat such issues, the urban communities are being modified by presenting shrewd feasible procedures.
\end{abstract}

There are various advantages straightforwardly joined to the manageability estimating apparatus such as to limit the natural impression of city, oblige populace development, and protect personal satisfaction of metropolitan occupants today and in future. It additionally assists financial backers with settling on a decision of their area, helps urban communities by being a directing soul to enroll different qualities and shortcomings of the urban communities and in this way helping them in progress by chipping away at their shortcomings and in characterizing and arranging their objectives and to plan pointed toward supporting their involved position and to foster arrangement for what's to come.

Keywords: Renewability; Tool for Environmental; Index of Sustainability; Environment; Monitoring Indicator;

\section{Introduction}

While the worldwide population is developing at fast speed in course of recent many years, urban communities experience various issues, fulfilling the mass, explicitly regarding foundation. The test is to resolve these issues and to address the issues of every individual while giving personal satisfaction and maintainable turn of events.

Further, different classes and Indicators were created to set up a rating list concerning Indian setting and a short time later, 110 markers were achieved[1]. Above mentioned markers were examined hard to carry out for the making of an Rating Index of Metropolitan City as the majority of the pointers were got through worldwide lists and the suggested file should not create precise outcomes. After a far reaching study it was chosen to chip away at a specific space of different classifications that will uncover any natural associated state of city and its adverse consequence, assisting the city with understanding wherever it is lacking and how it tends to be powered[2]. Thus, Renewability was settled that is based on the guideline of climate, financial (benefit) and gregarious (persons)[3].

The rating of city can likewise go about when a stage to feature the power of a specific city and subsequently enhancing the global and public picture of the city.

Different advantages identified with the rankings are:

1. Ranking goes about as a serious stage for examination.

2. It can act in deciding different qualities and shortcomings.

3. Perform as a device for subsequent degree and upgrades.

The exploration function started through an intensive investigation of the savvy metropolitan and the boundaries, likewise contemplating and examining different files accessible overall identifying with the setting of metropolitan rankings[4]. Given that marker's large portion has been acquired through overall files, it has been inferred that their reception for the making of Rating Index of Metropolitan City couldn't deliver

* Corresponding author: akshay.dhawan2789@gmail.com 
satisfactory outcomes as the information identified with the vast majority of the pointers were not really in India $n$ setting, subsequently it was finished that it will be a lot of valuable if the center stays in a single specific space of different classes concluded for the Rating Index of Metropolitan City and the settled classification was chosen as Renewability[5].

Thus Index of Asiatic Ecofriendly City has been chosen like a source of perspective Indicator framework while it consolidated central point and markers identified with the Asiatic framework, moreover assistance was caputred from BIS Indicator and different Indexes identified with supportability was captured through it to foster a rating Index Ecofriendly City for the Indian Framework.

Singh and Arora[6] A brilliant urban is an urban that underscore on the comprehensive advancement from the manageability decrease in the contamination, execution of Technology of Information to the greatest degree, great vehicle availability or shrewd portability and furthermore give adequate business and open position to its inhabitants. Keen urban areas are the prospective and forming it necessitates endeavors from both Govt. just like from residents.

M. Sethi[7] Exploration uncovers that notwithstanding possessing a Conventional meaning of a keen metropolitan in India, it owns degree to pull out greatest advantage as far as supportability, effectiveness, financial development and administration and this should be possible if the impending savvy urban areas center around feasible urbanization, great administration, straightforward measurements, announcing keeping individuals at the front.

V. Upadhyaya[8] The creator talks about the requirement for improvement to oblige the quickly expanding populace and consequently clarified the essential thought of keen urban communities with its part and relevance in our urban areas. The different parts for improvement of savvy urban areas have been recognized and these are keen vehicle the executives, squander the board, water reusing, brilliant schooling, shrewd administration, keen energy, keen structures, keen road lightings and keen IT and interchanges framework. It presumes that a keen city isn't just about digitization yet is tied in with giving expense effective, reasonable and economical answers for its inhabitants.

\section{Research methodology}

The Ecofriendly City Index estimates the ongoing ecological presentation of urban communities of India, just like urban communities endeavor in diminishing future natural effect. This ranking framework would be the initial move in order to achieve the advancement of fruitful Metropolitan City.
The system created depends on crafted by before Asiatic Ecofriendly City Index created through the EIU with Siemens participation in it, which is now canvassed in the writing audit section. With respect to pertinent to Indian city, the design is being adjusted so as to oblige varieties in information characteristics and accessibility, and ecological provokes explicit to the Nation[9]. In order to improve the information characteristics and to look for flawlessness the files in setting of India, Bureau of Indian Standards brilliant pointers of city, explicit to climate, $\mathrm{H} 2 \mathrm{O}$, squander, sterilization is likewise thought of. BIS gives standard to consumer loyalty and certainty on an item or administration. Subsequently BIS ends up being a dependable wellspring of pointers which can be utilized to gauge urban areas execution and further benchmark.

Joining every one of the markers from Asiatic Ecological City Index and BIS, a complete Indicator has been created that account urban communities throughout seven classifications - Carbon dioxide and Energy, transport, squander, Land use, $\mathrm{H} 2 \mathrm{O}$, sterilization and quality of air[10]. Every class includes a sum of 24 pointers individually, subsequent cautious choice and arranging based on information quality and accessibility. For the simplicity of information assortment and to guarantee greatest reliance on optional information, every one of the markers are stringently kept up as quantifiable information for instance urban water utilization per head[11].

The Indexes are chosen and planned such that the assortment of Data for the Metropolitan to be acheived can be effectively accessible on Govt. sites of native specialists and Study explicit sites like public and provincial insights.

The three systems which have been received are as per the following:

\subsection{Maxi- Mini Method}

The strategy is utilized for the ones pointer for whose the information of the base worth and greatest worth can be acquired through the approved govt. and review sites, utilizing the base and most extreme qualities (midst every one of the Cities of India) an Interlude track level is being formed that is additionally accustomed to ascertain the imprints relating to the ideal marker utilizing measurable technique for Interpolation to conclude last checks to that index[12]. For instance Carbon dioxide outflows per individual, the base Value for net zero is 0 structures and the most extreme worth that has been discovered was 4.80 tons per individual proportionately of India's Chennai, even when the greatest and the base worth of all the urban areas of India has been characterized, stretch the span scale the deduction can be derived concerning what 0-20 imprints implies, etc. further assume the urban radiates 3.0 huge loads of carbon dioxide per individual, utilizing the greatest and least qualities and introduction, the imprints relating to 3.0 could be determined without any problem. 


\subsection{Benchmarking}

The above technique is continued for the pointers that can be effectively changed on to rate, according to the strategy a limit of one hundred percent is acquied and thus corresponding to least of zero percent is aquired, scores are apportioned according to the rate got by the urban and relating to this proportion, scores are assigned. For instance level of strong refuse reused, the marker is clear as crystal and it very well may be effortlessly gathered that according to the idealistic situation it ought to be 100 percent, so all imprints are allocated to one hundred percent and none imprints are dispensed to zero percent, moreover the rate that has been got by any city can undoubtedly provide the comparing detriments for that and subsequently checks are achieved[13].

\subsection{Predefined category by government websites}

According to the above technique different classes has been as of now characterized by government, at that point according to the quantity of classifications, the stretch scale is arranged comparing to that classification lastly the information got for any urban is determined on to scores by investigating the span level the information drops within. For instance $\mathrm{NiO} 2$ focus scales, the accompanying classifications are now characterized by govt., thus comparing scores has been allocated to a particular class, and moreover interjection is utilized by investigating the stretch level the informational indexes drop in:

$\begin{array}{cll}\text { Great }(0-49) & : & 100 \\ \text { Acceptable }(50-99) & : & 80 \\ \text { Average }(100-199) & : & 60 \\ \text { Inadequate }(200-299): & 40 \\ \text { Very Inadequate }(300-399): & 20 \\ \text { Extreme }(400-499): & 0\end{array}$

\subsection{Classification Evaluation Techniques}

Alongwith the assistance of the previously stated techniques, different boundaries of the file are planned and assessed as arranged underneath:

2.4.1 Energy and CO2: Thinking about the information accessibility and reasonableness according to the Framework of India, 3 pointers has been chosen in this specific class, the first is Carbon Dioxide outflows per individual that is being captured from Asiatic Ecofriendly city Index, the technique that is being utilized is smaller than usual maximum for this marker, the subsequent pointer is Proportion of Energy Retrieved in Total through Sources which are Renewable, while a Total Energy Consumption of City is being shared, this marker is being captured through Index of BIS and Land marking has been utilized for Scores distribution[14]. The $3^{\text {rd }}$ pointer is Use of Total Electrical Energy per Individual (kilo watt/each Year) through the Index of BIS for what little max technique is being utilized.
2.4.2 Land Use and Buildings: According to the pertinence in setting of India, 2 pointers are being chosen following this class with Ecofriendly Spaces per individual being the first that is being captured from Asiatic Ecofriendly City Index, the technique for scores circulation captured is small scale max, according to which most extreme characteristics of hundred is being dispensed to city possessing ecofriendly stretch of $59 \mathrm{sqm}$ per occupant while zero imprints to urban areas possessing a space of zero sqm per occupant. The subsequent marker picked is thickness of Population that again is being capture through the Asiatic Ecofriendly City Index for whom the strategy for little max is being utilized once more, granting least signs of zero to city having most extreme thickness of ten thousand individuals for every sq. $\mathrm{km}$ while greatest signs of hundred to the Kapurthala city with least thickness of five hundred.

2.4.3 Transport: Thinking about the information accessibility and appropriateness according to the Framework of India, 3 pointers are being chosen within this specific class, first is the Mean Distance per vehicle trip (Dependent on car) that is being captured through the index of BIS, the strategy chose is smaller than expected maximum with the greatest signs of hundred distributed to the urban having least dependent behavior. The subsequent pointer chose is count of individual autos per individual (engine vehicles per thousand population) that is likewise captured through the index of BIS, strategy pursued is small scale maximum with the base imprints provided to the urban possessing greatest unit[1]. The $3^{\text {rd }}$ pointer chose is Social vehicle trips per individual each day that again is captured through Index of BIS, technique tracked is smaller than usual maximum beside the base imprints provided to the city possessing least portion of zero as the most extreme imprints are being provided to the urban with greatest portion of two.

2.4.4 Waste: According to the reasonableness in setting of India, 3 pointers are being chosen following this class beside the first being residue created per individual, captured from Asiatic Ecofriendly City Index, the stamping plan depends on small scale maxi strategy beside the greatest being $0.79 \mathrm{~kg}$ per individual however the imprints are being distributed as zero for one and hundred for zero. The 2 nd aspect that is the Proportion of absolute gathered city strong residue is captured through the Index of BIS with the idealistic state of one hundred percent consequently providing maximum signs of hundred and zero imprints to $0 \%$. The $3^{\text {rd }}$ aspect that is being accomplished by the Index of BIS is Proportion of the strong residue of city which is reused with the idealistic state of one hundred percent along these lines providing maximum signs of hundred and zero imprints to zero percent.

2.4.5 Water: According to the accessibility of the information, 2 pointers are being chosen following this classification beside the first being $\mathrm{H} 2 \mathrm{O}$ utilization per 
individual, captured from Asiatic Ecofriendly city file, the checking plan depends on smaller than expected maxi technique with the most extreme cutoff and least breaking point being five hundred Liter per capita and one hundred Liter per capita individually, when determined in NBC and the relating scores allocated for the greatest and least breaking point is one hundred and zero separately. The 2nd marker that is being concluded through the Index of BIS is Proportion of population of city with versatile supply of $\mathrm{H} 2 \mathrm{O}$ administration beside the idealistic condition and landmark of one hundred percent subsequently providing maximum characteristics of one hundred and zero imprints to zero percent.

2.4.6 Sanitation: Thinking about the information accessibility and reasonableness according to the Framework of India, 3 markers are being chosen in this specific classification; the first is proportion of population with admittance to improved sterilization. The main marker is assessed with one hundred landmark stamping plan by dispensing one hundred imprints to one hundred and zero imprints to zero percent. The 2 nd pointer that is being concluded through the Index of BIS is Share of sewage $\mathrm{H} 2 \mathrm{O}$ processed with the idealistic state of one hundred percent in this way providing maximum characteristics of one hundred and zero imprints to zero percent. The 3rd pointer is likewise concluded through the Index of BIS with proportion of population of city supplied by waste $\mathrm{H} 2 \mathrm{O}$ (squander water) assortment framework. The end pointer of the above classification is likewise assessed with one hundred percent benchmark stamping plan by dispensing one hundred imprints to one hundred percent and zero imprints to zero percent.

2.4.7 Air Quality: The air's nature is a proportion of how bad or unadulterated the air is. Analyzing the quality of air is significant on the grounds that the air that is being contaminated could be terrible for the strength of the climate and the humanity. The air Quality depends on the estimation of particulates matter (PM3.2 and PM12), Nitrogen Dioxide, Ozone, Carbon Monoxide and Sulfur Dioxide emanations like determined in Control Board of Central Pollution (CPCB). In light of the previously stated rules, 6 pointers that has been settled following this classification that is being basic in both Asiatic Ecofriendly city file and the Index of BIS. The 6 markers in particular, Nitrogen dioxide fixation levels, sulphur dioxide focus levels, PM3.2 fixation, PM12 fixation, Carbon oxide (Greenhouse gas emanation), Index of Quality of Air. The checking plan of the multitude of six pointers depend on the Minimum to Maximum strategy for assessment, in which greatest cutoff is determined as 500 and least breaking point is 0 according to the $\mathrm{CPCB}$ Guidelines. As far as possible is distributed 0 imprints and as far as possible is allocated 100 imprints.

The City Category Results of Delhi can be seen in figure 1 and Chandigarh in figure 2.

Based on the factors, the examination of supportability record of Chandigarh and Delhi is appeared in table no. 1 .

Table 1. The comparison of sustainability index of Indian Metropolitan Cities

\begin{tabular}{|c|c|c|c|c|c|c|c|c|}
\hline CATEGORY & INDICATOR & $\begin{array}{c}\text { SCORES } \\
\text { DISTRIBUTION } \\
\end{array}$ & DELHI & SOURCES & $\begin{array}{c}\text { SCORES } \\
\text { OBTAINED } \\
\end{array}$ & CHANDIGARH & SOURCES & $\begin{array}{c}\text { SCORES } \\
\text { OBTAINED }\end{array}$ \\
\hline \multirow{3}{*}{$\begin{array}{l}\text { Energy and } \\
\mathrm{CO}_{2}\end{array}$} & $\begin{array}{l}\text { Carbon dioxide } \\
\text { emissions per } \\
\text { individual }\end{array}$ & $\begin{array}{c}\text { Emission(Tonnes } \\
\text { per capita) - } \\
\text { Scores) } \\
0-98 \\
1-78 \\
2-58 \\
3-38 \\
4-18 \\
5-0\end{array}$ & 2.58 & $\begin{array}{c}\text { http://citycarbo } \\
\mathrm{n} \\
\text { footprints.info/ } \\
\text { GGMCF_top5 } \\
00 \\
\text { cities.txt }\end{array}$ & 48 & 3.5 & $\begin{array}{l}\text { Chandigar } \\
\text { h.govt.in }\end{array}$ & 30 \\
\hline & $\begin{array}{c}\text { Proportion of } \\
\text { Total Energy } \\
\text { Derived through } \\
\text { sources which } \\
\text { are Renewable, } \\
\text { as a share of the } \\
\text { Energy } \\
\text { Consumption of } \\
\text { City beingTotal }\end{array}$ & $\begin{array}{c}\text { (Part of } \\
\text { percentage }(\%)- \\
\text { scores) } \\
99-99 \\
79-79 \\
59-59 \\
39-39 \\
19-19 \\
0-0\end{array}$ & 27.72 & $\begin{array}{l}\text { Ministry of } \\
\text { Program } \\
\text { Implementatio } \\
\mathrm{n} \text { and } \\
\text { statistics }\end{array}$ & 27.7 & 84.3 & $\begin{array}{l}\text { Indian } \\
\text { Govt. } \\
\text { Ministry of } \\
\text { New and } \\
\text { Renewable } \\
\text { Energy }\end{array}$ & 843 \\
\hline & $\begin{array}{l}\text { Use of Total } \\
\text { Electrical } \\
\text { Energy } \\
\text { per individual } \\
\text { (Kilo watt hour } \\
\text { per Year) }\end{array}$ & $\begin{array}{c}\text { (Kilo Watt Hour } \\
\text { /Per year - Scores) } \\
300-720: 99 \\
720-1140: 79 \\
1140-1560: 59 \\
1560-1980: 39 \\
1980-2400: 19\end{array}$ & 1572 & $\begin{array}{l}\text { Center for } \\
\text { Science and } \\
\text { Commerce }\end{array}$ & 更 & 1601 & $\begin{array}{l}\text { State } \\
\text { Minister for } \\
\text { New \& } \\
\text { Energy } \\
\text { which is } \\
\text { Renewable, } \\
\text { Coal and } \\
\text { Power }\end{array}$ & $\begin{array}{c}38.0476190 \\
5\end{array}$ \\
\hline $\begin{array}{l}\text { Land use } \\
\text { and } \\
\text { Buildings }\end{array}$ & $\begin{array}{l}\text { Ecofriendly } \\
\text { facets per } \\
\text { individual }\end{array}$ & $\begin{array}{c}\text { (Square Meter per } \\
\text { inhabitant - } \\
\text { Scores) }\end{array}$ & 20 & $\begin{array}{c}19 \% \text { of the total } \\
\text { city area of land } \\
\text { of } 44,777\end{array}$ & 36.66666667 & 55 & $\begin{array}{l}\text { Chandigar } \\
\text { h.govt.in }\end{array}$ & $\begin{array}{l}91.6666666 \\
7\end{array}$ \\
\hline
\end{tabular}




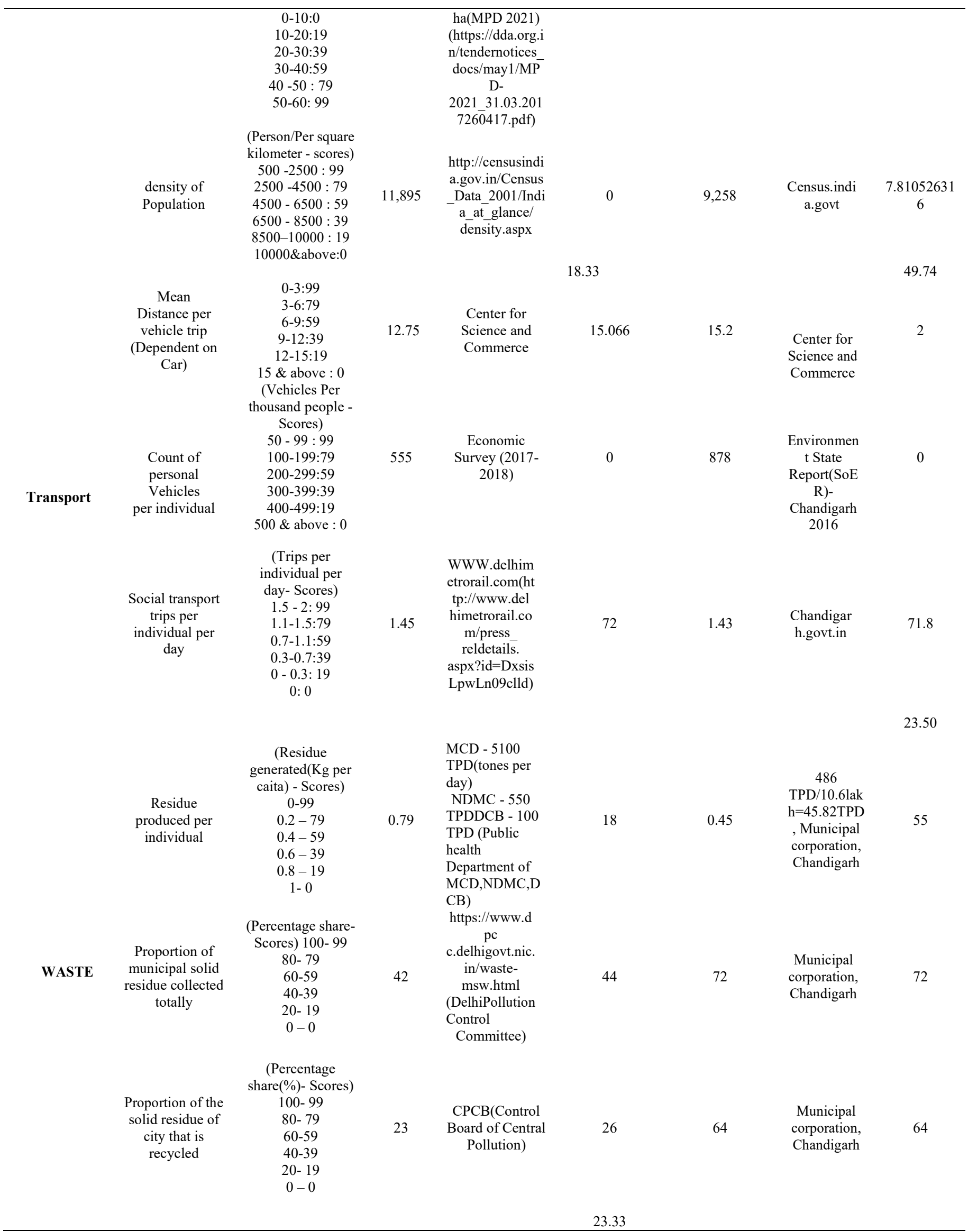




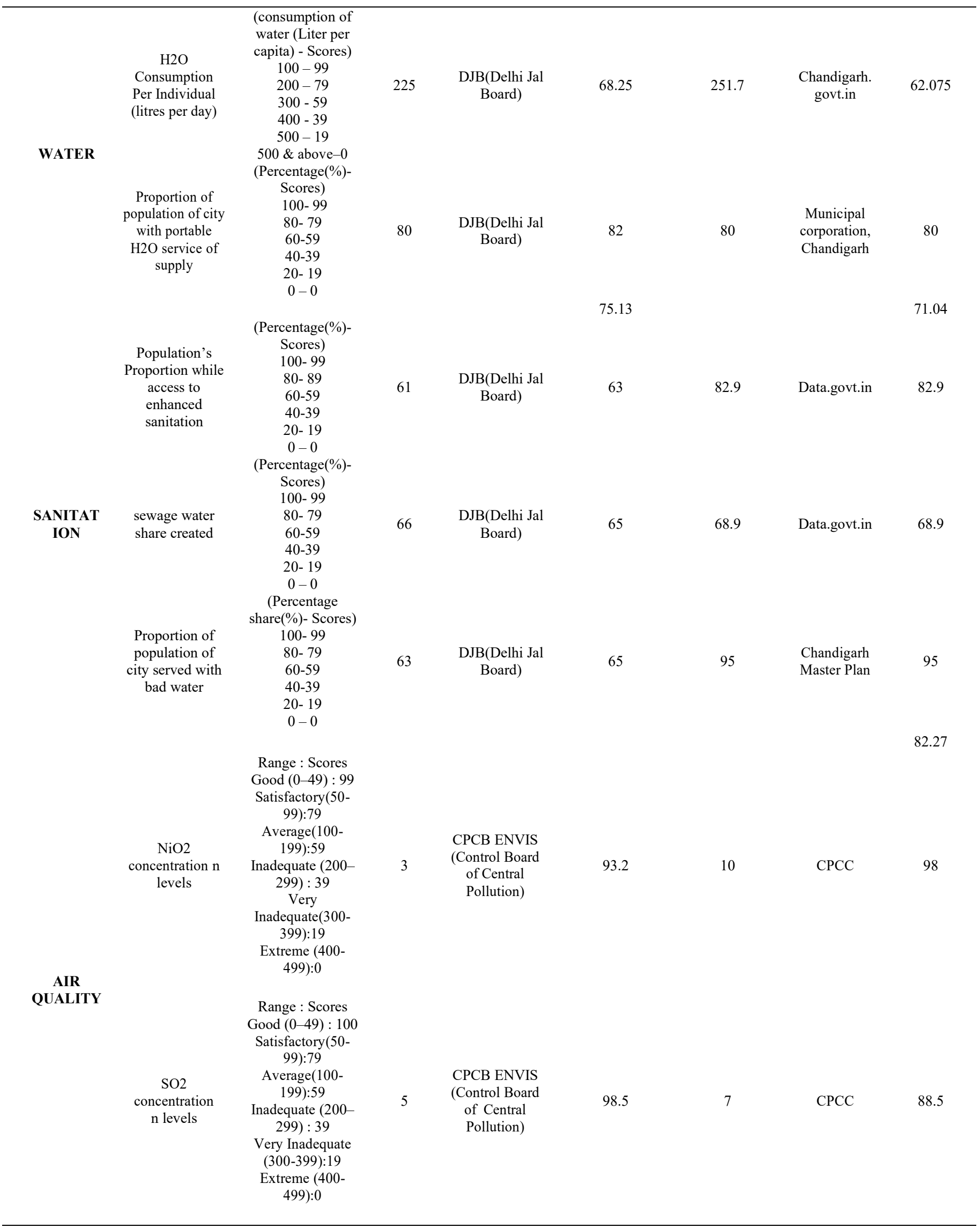


Range : Scores

Good $(0-49): 100$

Satisfactory $(50$ -

99):79

Particulate Average(100-

Matter

(PM3.2)

Concentration

$$
\text { 199):59 }
$$

Inadequate $(200$

299) : 39

Very Inadequate

(300-399): 19

Extreme (400 499):0

Range : Scores

Good (0-49) : 99

Satisfactory $(50$ -

$$
\text { 99):79 }
$$

Average $(100-$

Particular

Matter

(PM12)

Concentration

nadequate (200-

299) : 39

Very

Inadequate $(300$ -

399): 19

Extreme (400-

499):0

Range : Scores

Good (0-49) : 99

Satisfactory (5099):79

Average(100

$$
\text { 199):59 }
$$

Emission of

Green

House Gas

Measured in

Tones per

individual

(carbon

monoxide)

Index of Air

Quality

$$
\text { 299) : } 39
$$$$
\text { Very }
$$

Inadequate(300-

399):19

Extreme (400

$$
\text { 499):0 }
$$

Range : Scores

Good (0-49) : 99

Satisfactory $(50$ -

$$
\text { 99):79 }
$$

Average(100

$$
\text { 199):59 }
$$

Inadequate (200299) : 39 Very

Inadequate(300-

$$
\text { 399):19 }
$$

Extreme(400-

499):0
CPCB ENVIS

(Control Board

of Central

29.6

18

CPCC

96.4

CPCB ENVIS

(Control Board

of Central

Pollution)

54.6

36

CPCC

CPCB ENVIS

(Control Board

of Central

88.4

3

CPCC

99.4

Pollution)

CPCB ENVIS

Control Board

of Central

29.6

Pollution)

62

https://air-

quality.com

$/ \mathrm{pl}$

ace/india/ch

an

digarh/50e5

51

79.5

ed?lang=en

\&s

tandard $=$ aqi

${ }_{\mathrm{s}}^{\mathrm{u}}$ 


\section{City Category Results}
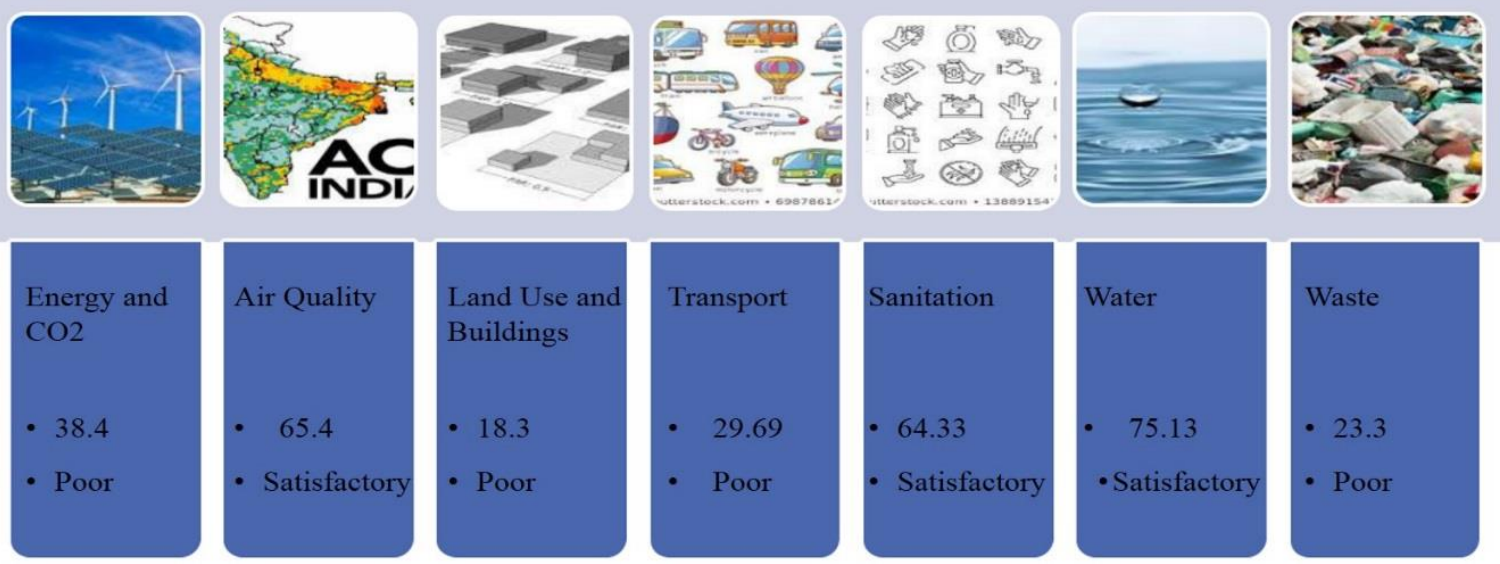

Figure 1. Category Result of Delhi

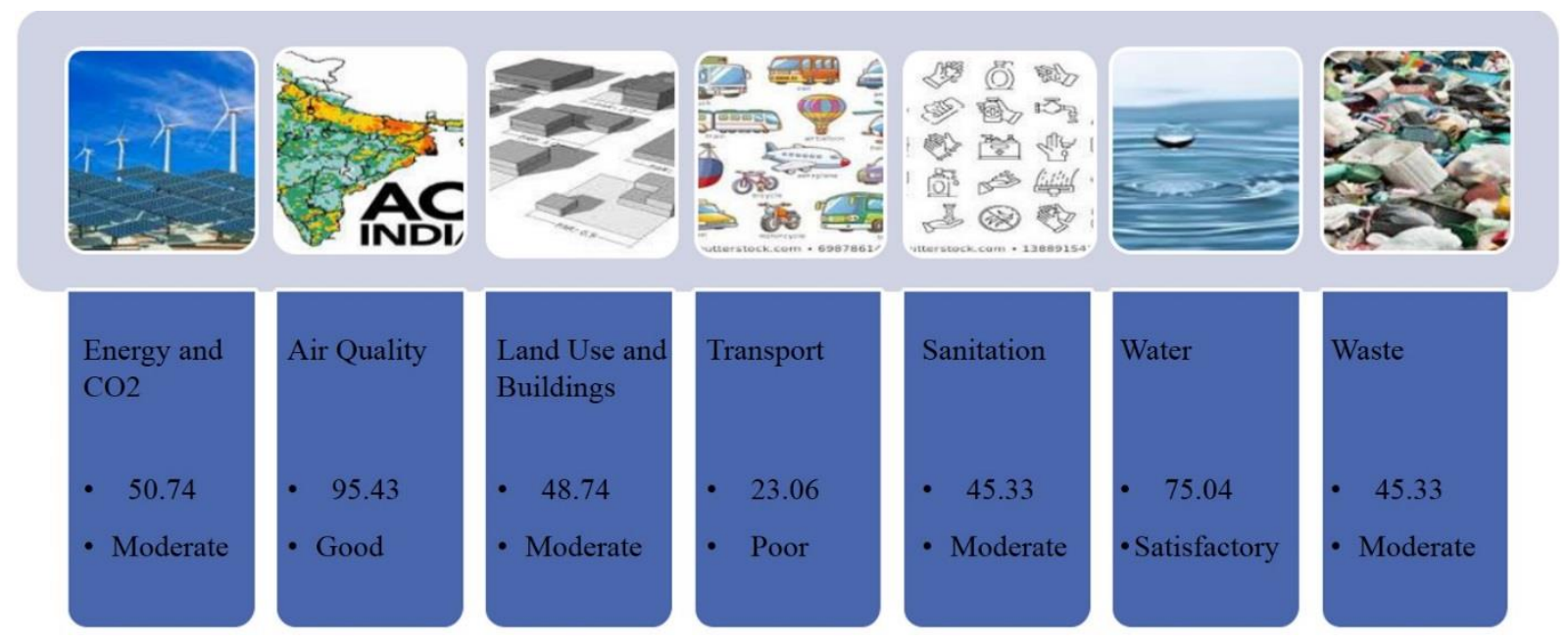

Figure 2. Category Result of Chandigarh

\section{Conclusion}

Ecological Renewability is characterized as the connection along with the climate to keep away from assets accessible in environment and furthermore to enhance the quality of nature. For instance, environmentally friendly power, as sunlight based, wind and force as opposed to relying upon nonenvironmentally friendly power sources which cause a ton of contamination. Climate medical care and maintainability are natively interrelated as the ecological quality straightforwardly influences general wellbeing. Alongwith the assistance of the Index of Renewability, partners can rate and rank any city of India regarding the 7 classes to be specific:, Water, Air quality, Transport, Sanitation, Land use and building, Waste and Energy and $\mathrm{CO} 2$. Every one of the classes structure the fundamental mainstay of any manageability of city. It would end up being a useful device focusing on different more vulnerable areas of a city to improve nature of way of life and medical services of the general public. This instrument could be utilized by the partners to landmark any city which is performing great and to define an 
objective for other urban areas of India to accomplish. This instrument can likewise be utilized by different govt. specialists and the city's civil branch, to form arrangements and methodologies for the classification where the city has marked lowest checks.

Beside the assistance of the device, any city of India could be surveyed on natural manageability and the space where there is an extent of progress could be resolved. For instance, in this paper, we thought about 2 urban areas Chandigarh and Delhi and inferred that Delhi require more dependency more on inexhaustible wellsprings of energy creation and Chandigarh needs to concoct new systems to decrease its carbon dioxide creation by tremendous thickness of vehicle.

\subsection{Research's Contribution}

The Renewability Index would be a ranking and land marking device for the ecofriendly urban areas on similar state as Leadership in Environment and Energy that is additionally a land marking instrument for the ecofriendly structure. The Leadership in Energy and Environment extension is kept to structures where the rating of specific platinum building is considered attractive and any remaining structures are planned on similar lines. Likewise, profoundly appraised city in the maintainability Indicator would likewise be viewed as an idealistic one and the development of any remaining urban areas will follow similar lines. Thus in this manner it adequately adds to the Industry by providing it a first since forever device to quantify the city's ecological presentation.

For the partners, it turns into a great need to become more acquainted with around the conditions which are natural and different variables and spaces which influence a wellbeing of city before putting resources into that specific city, different measures are considered however the manageability angle is scarcely taken care of. This apparatus furnishes them with all that data which helps them in taking a consistent choice by looking at all the accessible choices of any remaining urban communities.

\subsection{Limitations and Recommendations}

The supportability Index's plan incorporates number of limits that ought to be dealt with prior to directing further exploration on the apparatus. Right off the bat, the supportability apparatus is explicit to Indian urban communities and the classifications and pointers are finished according to Indian setting. Besides, components and markers are separated and arranged according to information accessibility and unwavering quality. Likewise, equivalent weightages are given to every one of the markers regardless of their adequacy to explicit urban communities. Thirdly, all the exploration work depend fundamentally on auxiliary information and no essential information is gathered and broke down for settling the classification and supporting pointers. As essential information assortment would need a gigantic capital, human and time asset and assortment and examination. It is suggested that for additional examination, essential information ought to be gathered from wide sources to arrive at more solid elements and to set up the genuineness of the outcomes accomplished. In conclusion, straight insertion is utilized in the scale for the assignment of imprints to every marker except in a portion of the classification, direct interjection won't be the legitimate technique for estimation. For instance, in the classification air quality, information will frame an $\mathrm{S}$ bend, subsequently direct introduction won't give genuine outcomes. It is prescribed to do escalated field examination of the city to be scored to gather essential information as opposed to relying upon the optional information.

\section{References}

[1] P. Maidan and N. E. W. D. May, "6 th Smart Cities India 2020 Expo Developing Smart Cities for our Citizens Smart Tech with India 's Urban Planning," no. May, 2020.

[2] R. Aijaz, Challenge of making smart cities in India, vol. 87, no. October. 2016.

[3] S. Bhattacharya and S. Rathi, "Reconceptualising Smart Cities: A Reference Framework for India," Cent. Study Sci. Technol. Policy, vol. September, p. 80, 2015.

[4] A. Randhawa and A. Kumar, "Exploring sustainability of smart development initiatives in India," Int. J. Sustain. Built Environ., vol. 6, no. 2, pp. 701-710, 2017

[5] USIBC, “A Nation of Smart Cities," An Ind. Discuss. White Pap., pp. 1-21, 2014.

[6] I. Journal, J. S. Arora, and N. Singh, "a Review Paper on Modernization of a City Into Smart City," vol. 4, no. 3. pp. 93-95, 2016.

[7] M. Sethi, "Smart Cities in India : Challenges," no. September 2015, 2017.

[8] V. Upadhyaya, "Smart Cities : A Vision for Development of Indian Cities," Imp. J. Interdiscip. Res., vol. 2, no. 10, 2016.

[9] KPMG, "Internet of Things in Smart cities," no. May, p. 20, 2019.

[10] S. Joshi, S. Saxena, T. Godbole, and Shreya, "Developing Smart Cities: An Integrated Framework," Procedia Comput. Sci., vol. 93, no. September, pp. 902-909, 2016

[11] R. E. Hall, "The vision of a smart city The Vision of A Smart City 2nd International Upton, New York, U . S . A ., 11973," no. January 2000, 2015.

[12] O. Parishwad and T. Singh, "Analysing and Rating Smart City," J. Civ. Eng. Environ. Technol., vol. 1, no. 6, pp. 54-59, 2014.

[13] Seconded European Standardization Expert in India (SESEI), "Report on Smart City MissionIndia," 2018.

[14] R. Dwevedi, V. Krishna, and A. Kumar, "Environment and big data: Role in smart cities of India," Resources, vol. 7, no. 4, pp. 1-10, 2018. 